\title{
Sobre El Barroco Literario Hispánico
}

He leído la reseña escrita por el Profesor Alexander A. Parker. sobre mi libro El barroco literario bispánico. No es mi costumbre responder a las reseñas de mis obras, pero ésta me cita de tal manera y - creoof rece equivocaciones que obligan a una respuesta de mi parte.

Es indudable ( $\mathrm{y}$ no pretendo remedar el inocente humorismo del Sr. Parker) que éste no está de acuerdo con mi libro. Claro que tal deseencuentro no le da derecho para hacerme decir lo que yo no digo. En fin, cuestiono también el "método" de la reseña, típico método de sastre (de tijera y alfileres) y que, sospecho, el autor no considera "an. ticuado".

1) La primera observación concreta da la pauta de las "fallas" que el reseñador encuentra en el libro. (Esta observación ocupa nada menos que uno de los seis pátrafos de la reseña). Uniendo líneas de la página 21 con líneas de la página 12, el reseñador establece su discrepancia. Lo curioso es que se trata de un aspecto muy sencillo, y en el cual, en lo que importa, el reseñador está también de acuerdo: la rehabilitación del concepto de barroquismo.

Lo que yo digo, textualmente, es lo que sigue:

Rebabilitación del Barroco. "No es ningún secreto el adelanto extraordinario que en nuestro siglo ( 0 , más exactamente, en los áltimos cucrenta años) ha ganado el concepto artístico de lo barroco..." (p. 11). $\mathrm{Y}$ después de puntualizar una serie de nombres en esa dirección, menciono, como negadores u opositores, los de Croce, Mauclair, Bell y Antonio Machado (p. 11).

No quiero ofender al reseñador sobre sus conocimientos de español. En todo caso, sí, sobre sus conocimientos de aritmética elemental: mi libro está fechado en 1968 (y salió en 1969). Dentro de esos cuarenta años puede incluirse, también, el artículo de Mauclair (de 1930).

Además, el reseñador no tiene en cuenta otros nombres que cito (José F. Montesinos, M. Romera-Navarro, Alda Croce, etc.) y decide dictatorialmente que la oposición al barroco "ha sido borrada definitiva. 
mente hace ya muchos años". No tanto. Si el reseñador tiene curiosidad en leer la décimoctava edición del Dicrionario de la Academia (vale decir, la última edición, cuando apareció mi libro) leerái la siguiente definición:

Barroco. "Dícese del estilo de ornamentación caracterizado por la profusión de volutas, roleos y otros adornos en que predomina la linea curva. Por extensión se aplica también a las obras de pintura $y$ escultura donde son excesivos el movimiento de las figuras y el partido de los paños; y en el arte literario a toda obra en que predominan la pompa y el ornato".

2) $Y$, como consecuencia de lo precedente ¿de dónde ha sacado el reseñador que el punto de partida de mi libro está en el deseo de borrar definitivamente los juicios negativos? Si lee como corresponde, verá que, dando por sentada la rehabilitación del concepto, señalo que mi intento es trazar una caracterización de la literatura barroca hispánica y funda. mentar dichos caracteres (Pp. 22-23). Y en la conclusión digo que, sin desconocer la existencia de otros rasgos, defiendo los que estudié, apoyándome en textos de la época (p. 171). Esto está muy claro, pero el reseñador (de cuya perspicacia me permito dudar) parece no haber tenido presente mis palabras. No quiero pensar en un ejemplar defectuoso, o en hojas pegadas...

3) Por razones de claridad, seguiré con las "fallas" concretas que el reseñador encuentra en el libro. Al final me ocuparé de las de tipo general.

Dice la reseña:

De modo que al referirse a las "metáforas encadenadas o metáforas en serie" como una caracterización de esta literatura, el único ejemplo aducido es Góngora.

Aquí el método utilizado es el de la tijera. Lo increíble es que, aparte de Góngora, menciono los ejemplos siguientes: Quevedo (Fiesta de toros...), Domínguez Camargo ( $A$ un arroyo...), Bastidas ( $A$ un arroyo...), Ledesma ( $A$ la vida y muerte de Nuestro Señor. ., Coloquio pastoril..., Diálogo entre un filósofo ateniense gentil y un theólogo christiano...), Paravicino y Arteaga (Metáfora de un cedro a quien abrasó un rayo), Agustín de Salazar y Torres (Quéxase un amante...), Francisco Bueno (Al Santisimo en metáphora de tussón, Al Santísimo en metápbora de un torneo), Anónimo ( $A$ la conciencia en metáfora del 
reloj)... Como ve el reseñador, el ejemplo de Góngora no es el único...

4) Dice el reseñador:

Con más conocimiento de las investigaciones de los últimos veinte años, Carilla se hubiera ahorrado ideas y métodos anticuados... Ya no basta, por ejemplo, presentar como significativas estas definiciones (que en realidad no dicen nada): Cultismo: estilización plástica, belleza descriptiva; Conceptismo: sentencia y rasgo de ingenio, con ostentaciones expresivas.

Aquí, de nuevo, el método de tijera. Lo que yo digo es concretamente lo que sigue:

...no es esta diferencia radical [la que críticos del pasado establecieron entre cultismo y conceptismo f la que hoy mejor se defiende. De la misma manera, nos explicamos, por ejemplo, que Dámaso Alonso haya mostrado no hace mucho al cultismo como un particular conceptismo que agrega, sobre todo, un recargamento ornamental y sensorial. Creo, por mi parte (sin negar la distinción de Dámaso Alonso) que, esencialmente, la diferencia mayor entre cultismo y conceptismo se apoya así: Cultismo: estilización plástica, belleza descriptiva; Conceptismo: sentencia y rasgo de ingenio, con ostentaciones expresivas.

El reseñador no utiliza aquí el método de los alfileres, a que tan afecto es en otras ocasiones. Podría hacerlo, en relación a la "agudeza" (con menciones de Gracián y Tesauro, ver cap. II) y a la caracterización del cultismo (ver cap. V). Pero no lo hace.

En nota aparte de Dámaso Alonso, hago referencia a trabajos de Lapesa y Leo Spitzer, y también a varias obras mías (sobre todo, mi libro sobre Quevedo, de 1949). Sospecho vagamente que "entre las investigaciones de los últimos veinte años" el reseñador incluye (aunque no lo dice) algún estudio suyo. Después me ocuparé de él.

5) Destaca el reseñador:

En una nota a la página 96 se menciona el Cannoccbiale de Tesauro como importante testimonio sobre la significación de la me. táfora en la poesía barroca; pero en España existe la Agudeza de Gracián, que $\tan$ bien estudiada ha sido por T. E. May... etc.). 
Métọdo Ollendorff. Lo que yo digo, en la nota, es esto:

Sobre la metáfora y su significación en la poesía barroca en general (más allá de España y Góngora) ver el importante testimonio que aporta la obra de E. Tesauro, Il Cannochiale Aristotelico (1a. ed., Turin, 1654. Ver. ed. de 1670, p. 496)...

El reseñador puede creer en mi palabra (y por citas que hago de la Agudeza) de que conozco esta obra de Gracián...

6) Dice el reseñador:

Nadie, leyendo a Carilla, se daría cuenta de que hay valores filosófico-éticos en la literatura española. No estudia el neoestoicismo (también fenómeno internacional de la época)...

Respondo: nadie, leyendo la reseña, se daría cuenta de que el autor de la misma ha leído el libro en su totalidad. O' de que lo ha leído con juicio sereno.

Dentro de los diversos capítulos de la obra, creo tocar el tema en el dedicado a la contención (cap. II), al referirme al problema de la libertad en la literatura barroca (pp. 29-34; ver también "libertad y soledad", p. 152). $Y$, sobre todo, en los capítulos dedicados al desengaño terreno (cap. IX) e ideales religiosos (cap. X). Es fácil notar que allí hablo de "valores filosófico éticos". Imagino, además, que las conexiones religiosas no serán inconveniente para que se los acepte así.

Con respecto al neoestoicismo, si no me detengo ahora en la forma en que lo hice en mi libro Quevedo (pp. 65-68), algo digo en la última obra:

En fin..., la libertad que resume ideales del antiguo sabio: es libre el que conoce, el que puede elegir entre el bien y el mal, el que distingue su lugar en el mundo, el que sabe despreciar halagos y riquezas. Reflejos, casi siempre de lecturas, y particularmente, de lecturas donde se condensan doctrinas de los estoicos. (Aunque no mencione siempre el vocablo, nos sirven de ejemplo versos y prosa de Quevedo) (p. 31).

7) Dice el reseñador:

...y demuestra profunda incomprensión del desengaño al definirlo como "el cansancio, el hastío, la insatisfacción; se cree haber gus- 
tado ya todo". Iba a ser esto para el romanticismo; pero para el barroco era una valoración racional de las distintas maneras de distinguir entre la verdadera y la falsa felicidad. Segismundo desengañado, pero demasiado joven y con muy poca experiencia para ser hastiado, llega por medio del raciocinio a reconocer un imperativo ético que restaura la armonía en el estado revuelto de Polonia.

Vayamos por partes. En primer término, yo no "defino" el desengaño en la forma que me atribuye el reseñador. Yo señalo esas notas entre otras que la reseña omite. Digo, textualmente:

Dentro de la abundancia llamativa de los testimonios, vemos que tal abundancia en la época barroca es reflejo de una actitud anímica, de un sentimiento general. Sentimiento que descubre el cansancio, el hastío, la insatisfacción; se cree haber gustado todo, y haber llegado al límite de las cosas en el ámbito estrictamente terreno. $Y$ hay, si no una complacencia, por lo menos algo así como un ineludible deseo, casi obsesión, en mostrar — con realces literariosel agotamiento de las ilusiones, las cuotas de vanidad y de vacío que se esconden en la vida humana, la debilidad en que se apoyan la pompa y la magnificencia.

$Y$ más adelante:

Yo creo que en la visión pesimista del desengaño, que subraya aspectos del barroco español, contribuyen tanto las consecuencias de una realidad político social (sin exagerar demasiado sus reflejos en las expresiones artísticas) como la lección religiosa moral que vuelve incesantemente sobre los motivos de la ilusión, el orgullo, sobre la vanidad de las cosas terrenas... (etc.).

En el caso de La vida es sueño sospecho vagamente que el reseñador cree ver en mi libro una relación entre el hastío (p. 142) y el desengaño de Segismundo. Esto corre - alfileres y método Ollendorf-- por su cuenta exclusiva. Yo sólo digo de esta obra de Calderón (jy en la página 148!) lo siguiente:

Y ya que hablamos de Calderón conviene recordar (en razón de la importancia de la obra) que el desengaño es uno de los motivos fundamentales de La vida es sueño, y que no sólo alcanza a su protagonista, Segismundo. Prácticamente, llega hasta todos los per- 
sơnajes importantes de la comedia: Basilio, Clotaldo, Rosaura, Clarín, Astolfo, Estrella (con salvedades en el caso de Clotaldo y Rosaura). $Y$, en fin, que toca también a dos personajes anónimos como el criado segundo y el soldado de la escena final.

(Por último, tiemblo al pensar que quizás el insistir en "Segismundo, joven", dentro de la reseña, tenga algo que ver icon una cita de Schopenhauer que yo hago!).

Y a propósito del "hastio", en lugar del falso ejemplo de Segismundo, ¿por qué no buscar en obras de Alemán, Quevedo, Gracián y otras que señalo, mejores fundamentos?

8) En las consideraciones de tipo general, no entiendo qué quiere decir el reseñador con conclusiones de "actualidad". Las conclusiones se fundamentan o no se fundamentan, valen o no valen. Tampoco saco mucha luz sobre qué es lo "anticuado" o lo "no anticuado".

"Hace medio siglo — dice - se vienen señalando por lo menos cuatro de estas características" (es decir, de las que yo apunto). Podríamos deducir que si "se vienen señalando" guardan aún alguna actualidad. Pero sigamos. La afirmación escueta da la impresión de que el reseñador "descubre" esos precedentes con anterioridad a mi libro, cuando yo, en realidad, los destaco. Claro que hubiera correspondido aclarar si me limito a repetir simplemente lo que han dicho los demás.

En este sector, confieso que me puse triste cuando el reseñador en. contró "cierta originalidad" al primer rasgo que analizo. Afortunadamente, los reparos posteriores me consolaron...

Con respecto al método y la bibliografía de mi libro, sospecho que la prisa o la ofuscación no le permitieron al autor de la reseña leer el primer párrafo de la conclusión de la obra (cap. X):

Sería pedantería de mi parte y, al mismo tiempo, caer en las limitaciones que combato, el afirmar que dentro de los caracteres precedentes se encierra toda la literatura barroca. La verdad que no. Sólo defiendo, con ellos, lo que me parece se deduce o desprende de un caudal apreciable de obras que se escribieron durante el siglo xVII en España y en América, y que aceptamos como barrocas. De manera especial -aclaro- aquellas que consideramos valiosas e individualizadoras (p. 171).

Por un lado, pues, el reseñador parece olvidar esto. Por otro, me achaca que me restrinja "casi exclusivamente a la lírica". Pero no, en 
realidad, se queja de que yo haga poco caso de "los múltiples estudios" que se han hecho últimamente sobre la novela y el drama. Sobre todo, de críticos de lengua inglesa.

Como vemos, las ramificaciones son variadas. En primer término, si bien abundo en ejemplos de la lírica (cuya importancia sería torpe negar), no creo que me olvide de la novela y el teatro, aunque concedo la desigualdad. $Y$, en segundo lugar, procuro abarcar una bibliografía sobre el barroco que, como señalo, considero "importante (o, por lo menos, significativa)". No es, claro está, un catálogo y, por pudor, no repetiré los nombres, aunque al reseñador no le parecen importantes. Éste habla de "bibliografía completa". Me gustaría saber cuál es el concepto de "bibliografía completa" que tiene, y cómo lo defiende.

Sin salir de este sector, opino que el libro de Andrée Collard, Nueva poesía. Conceptismo, culteranismo en la crítica española (Madrid, 1967), que el autor de la reseña no menciona, supera ostensiblemente a los artículos (de T. E. May y Bethell) que yo omito y que me recrimina. Yo no pude utilizar el libro de Collard por explicables motivos de tiempo. Y como este caso hay algún otro.

No resulta aventurado sospechar que entre la bibliografía en lengua inglesa (o de hispanistas ingleses) que yo no menciono, y cuyo vacío el reseñador destaca, se encuentren trabajos suyos. Como su estudio sobre "La agudeza" en algunos sonetos de Quevedo. Contribución al estudio del conceptismo (publicado en Estudios dedicados Menéndez Pidal, III, Madrid, 1952, pp. 345-360), donde considera al conceptismo como la base de "todo el estilo barroco europeo", y al concepto, como una metáfora "violenta" o "disonante". Por supuesto, yo no pienso así, aunque es posible que, para el autor, este tributo sea ejemplo de método "no anticuado" y sus conclusiones sean de "actualidad"

Concluyo. Dejo a un lado, como ajeno, el sorprendente humorismo del reseñador. En fin, lo restante de la reseña me parece acertado.

\section{Emilio Carilla}

Universidad de Tucumán, Argentina 
